\title{
THERMO-VISCOELASTIC CHARACTERIZATION OF POLYMER LAMINATE FILMS
}

\author{
Eliza Truszkiewicz ${ }^{a, *}$, Daniel Tscharnuter $^{a}$, Gerald Pilz $^{b}$ \\ ${ }^{a}$ Polymer Competence Center Leoben GmbH, Rossegerstrasse 12, 8700 Leoben, Austria \\ ${ }^{b}$ Materials Science and Testing of Polymers, Montanuniversität Leoben, Otto Glöckel-Straße, 8700 Leoben, \\ Austria \\ * corresponding author: eliza.truszkiewicz@pccl.at
}

\begin{abstract}
The investigated material - laminate is intended as a substrate for small electronic components, electrodes and printed circuits, which are processed onto the laminate prior to thermoforming. The placement of the electronic components and the connecting circuits must be carefully designed to prevent damage during the thermoforming. The thermo-viscoelastic behavior of a polymer laminate film was characterized by mechanical measurements to obtain data for material modeling. The strain was measured using digital image correlation. The film is anisotropic and is able to deform to strains up to $60 \%$.
\end{abstract}

KEYWORDS: thermoviscoelasticity, polycarbonate, polyethylene terephthalate, dynamic mechanical analysis, tensile test, stress relaxation.

\section{INTRODUCTION}

The material investigated in this study is laminate film composed of a blend of polycarbonate and acrylonitrile butadiene styrene (PC-ABS) and polyethylene terephthalate (PET). The thermo-mechanical behavior of neat polycarbonate has been studied extensively, e.g. [1, 2. They have unique combination of the high processability of ABS and very good mechanical properties and heat resistance of PC. Blends of PC and ABS have also been the subjected of some scientific studies [3-5]. E.g. Greco et al. [4] have shown that the impact strength can be improved by adding $20 \%$ to $40 \%$ ABS and that tensile strength, Young's modulus and hardness decrease with increasing ABS content. Due the large variation in properties of different grades of a particular polymer or blend these data are not necessarily applicable for the present material. Additionally, the PC-ABS and PET films are stretched during manufacture, which introduces anisotropy in the material.

The laminate is intended as a substrate for small electronic components, electrodes and printed circuits, which are processed onto the laminate prior to thermoforming. The placement of the electronic components and the connecting circuits must be carefully designed to prevent damage during the thermoforming. The polymer laminate may be stretched substantially, but for e.g. copper, the fracture strain is approx. 10 to $12 \%$ and the ampacity may be compromised already at smaller deformation.

The major task is to conduct a thermo-viscoelastic characterization of the laminate to obtain data for a material model that may be used in finite element simulations of the thermoforming process. The parameters will be determined by measurements like uniaxial and biaxial tension testing, dynamic mechanical analysis (DMA) and thermomechanical analysis (TMA). In this part of the work the first measurements were conducted using Digital Image Correlation on a sample of the thermoformed laminate film (Figure 1) to determine the strain field for subsequent uniaxial tensile and relaxation tests. DMA was also conducted.

\section{The Thermoforming Process}

The thermoforming process is a non-isothermal process of converting a sheet into a three-dimensional shape. In the first step the laminate film is heated to the forming temperature, which may be slightly above or much larger than the glass transition temperature depending on the forming pressure. In next step the film is formed using pressurized air or vacuum. The mold temperature is chosen below the glass transition temperature. Due to the contact with the mold the film is cooled and the polymer chains are locked in their deformed state. When the desired shape is ready the film is removed from the mold. The thermo-viscoelastic behavior of the film is studied in a non-isothermal tensile test to imitate the heating, deforming and cooling steps of the thermoforming process.

\section{EXPERIMENTAL}

The thermo-viscoelastic behavior was characterized by dynamic mechanical analysis, monotonic tensile and relaxation tests for several temperatures and orientations. The dynamic mechanical analysis were carried out using a PerkinElmer DMA 8000. Other mechanical tests were performed using a Zwick/Roell Z250 testing machine equipped with a temperature 
chamber and using Digital Image Correlation (DIC; ARAMIS, GOM) for strain measurement [6].

A sample of the laminate film has been thermoformed using a generic mold. A millimeter grid has been printed on the film by the supplier. The millimeter grid may be used for strain measurement by DIC, however it lacks a unique feature for the tracking of motion in subsequent images. A traceable pattern was therefore created by filling points on the grid using a permanent marker. The same pattern was applied on undeformed grid paper, which was used as a reference sample, and on deformed film to measure the strain field after the thermoforming (Figure 1).

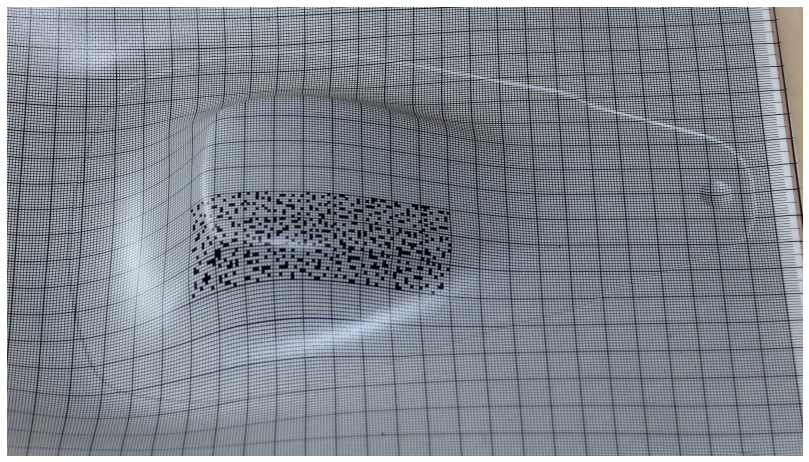

Figure 1. Coated laminate film.

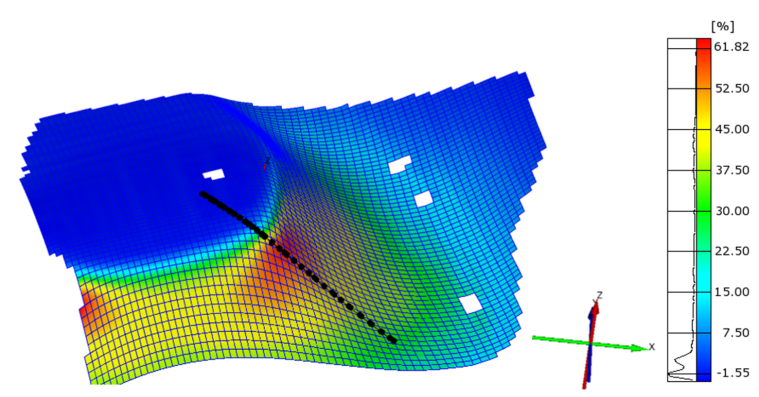

FigURE 2. Strain field on the thermoformed laminate film.

Figure 2 shows the major strain field as measured described above. There is almost no strain on the top, where the laminate film comes into contact with the mold first. The slopes lead to tensile strains of around $40 \%$. On the shoulders, additional shearing leads to major strains of up to $60 \%$. For the mechanical characterization, testing temperature varied between room temperature and $145^{\circ} \mathrm{C}$. Specimens were cut at angles of $0^{\circ}, 45^{\circ}$ and $90^{\circ}$ and spray-coated with a pattern for DIC. The monotonic tensile tests were performed with a nominal strain rate of $1 / 50 \mathrm{~mm} / \mathrm{s}$. The same rate was also used for the initial loading in the relaxation tests.

In a non-isothermal tensile test, the film is heated to $145^{\circ} \mathrm{C}$ without applied stress. In the next stage the specimen is stretched to a nominal strain of $25 \%$ and kept at this strain. The film is quickly cooled using cooling packs. The polymer chain mobility at the low temperature is strongly reduced and deformation of film is therfore locked. When the film is removed from the temperature chamber it retains this stretch. This part of the non-isothermal test is shown in Figure 3

The whole process takes about 15 minutes after the removal of the stretched and cooled specimen from the testing machine for the temperature to stabilize at $145^{\circ} \mathrm{C}$ again. In last step the specimen is placed again in the temperature chamber, but only the upper specimen grip is closed and in this specimen position the continuation of DIC strain measurement in again possible. The specimen is heated without external stress, which allows the viscoelastic part of the locked deformation to recover with time.

\section{Results}

Figure 3 shows the time-dependent recovery from nonisothermal tensile test. The effect of recovery behavior of the two materials is curling up the laminate - the $\mathrm{PC}$ layer of the film laminate recovers quickly, but it is constrainted because of the PET layer.

The rolled-up shape does not permit a DIC evaluation. When the laminate unfurls (the stresses have relaxed sufficiently) - the strain measurement can con-

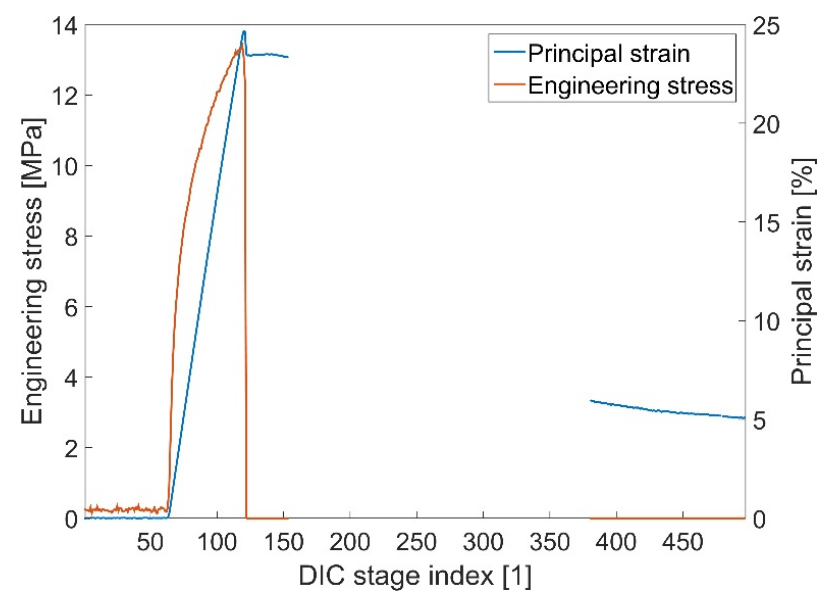

FIGURE 3. Non-isothermal tensile test with recovery to mimic the thermoforming process.

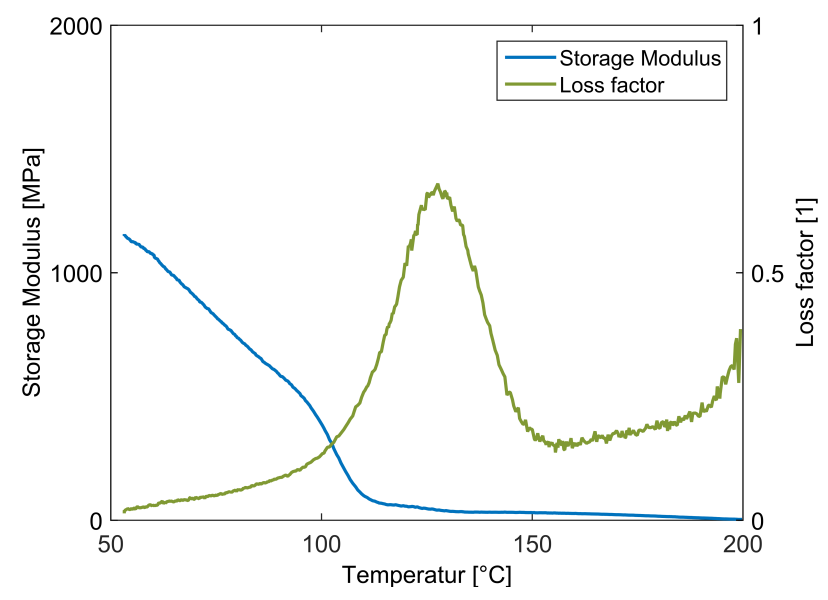

Figure 4. DMA results. 

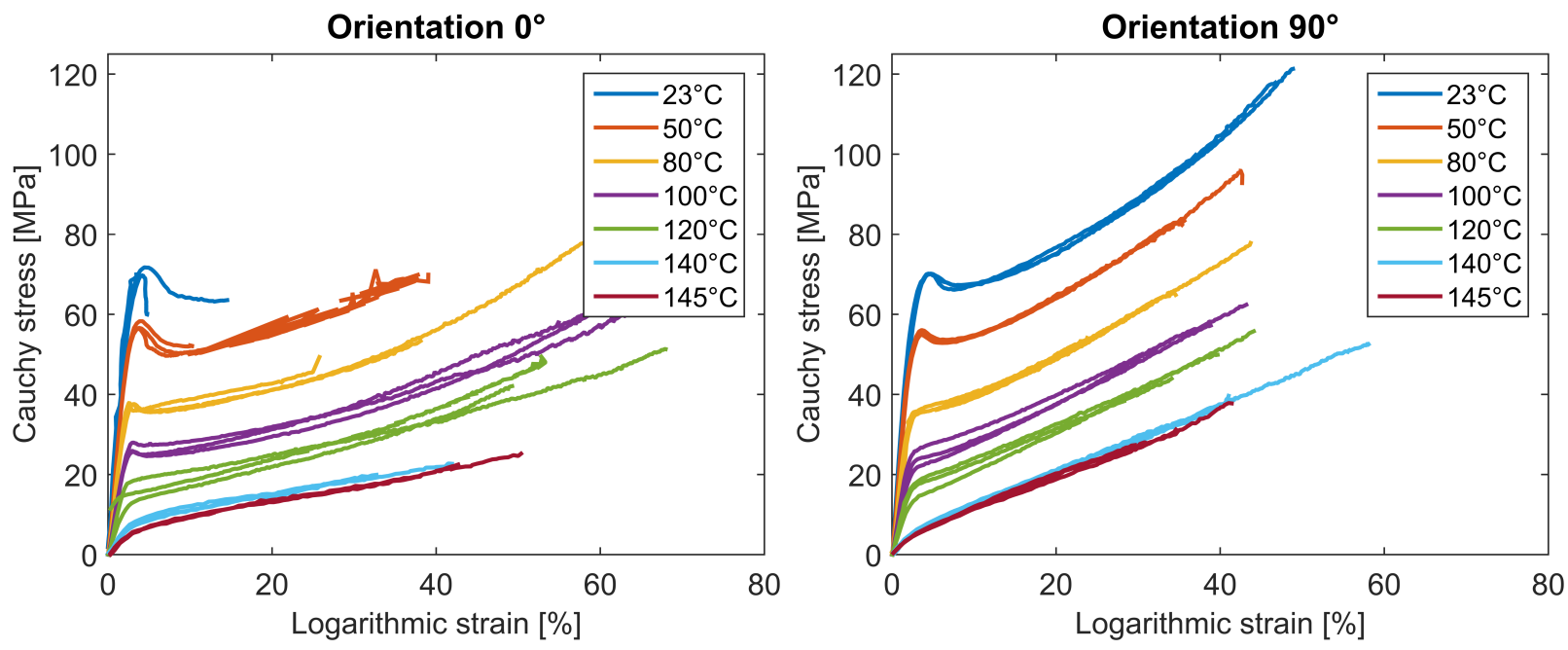

FiguRE 5. Relation between logarithmic strain and Cauchy stress - results for different orientation of specimen.


FiguRE 6. Relation between the Cauchy stress and time depends on temperature for $0^{\circ}$ and $90^{\circ}$.

tinue (Figure 3, starting at stage 381). We observe that $80 \%$ of the deformation is recovered in a short time by reheating the specimen. This test confirms the initial assumption that this thermoforming process creates predominantly viscoelastic deformation.

The glass-transition temperature was determined from the DMA measurements. The glass-transition of the laminate is defined by the glass-transition of the PC-ABS blend and is $122^{\circ} \mathrm{C}$ (for separte PC amounts around $145^{\circ} \mathrm{C}$ and $105^{\circ} \mathrm{C}$ for ABS [5]). A small peak at $80^{\circ} \mathrm{C}$ was observed (Figure 4), which is characteristic for the PET film [7]. Due to the high crystallinity of the PET film, the effect of this transition is small.

The tensile tests showed the expected strong temperature dependence (Figure 5), where the stress at a given strain decreases by a factor of 3 to 4 when raising the test temperature from $23^{\circ} \mathrm{C}$ to $145^{\circ} \mathrm{C}$.

The effect of orientations is pronounced for strains larger than $10 \%$. The ultimate stress at $145^{\circ} \mathrm{C}$ in the transverse direction is for example twice as high as in the extrusion direction, which indicates substantial stretching following the extrusion process.
Figure 6 shows the stress relaxation in $0^{\circ}$ and $90^{\circ}$ at approximately $40 \%$ strain for temperatures of $80^{\circ} \mathrm{C}$, $120^{\circ} \mathrm{C}$ and $145^{\circ} \mathrm{C}$. For all temperatures, we observe a significant amount of stress relaxation in the first seconds after the initial loading. The relaxation rate then decreases substantially, but the viscoelastic effects are still not negligible after $1000 \mathrm{~s}$ of relaxation.

\section{Conclusions}

A polymer laminate film was characterized to provide data for thermo-viscoelastic material modeling. The measurements covered temperatures from room temperature to $145^{\circ} \mathrm{C}$, which is approximately $20^{\circ} \mathrm{C}$ above the glass-transition temperature of the laminate. Significant anisotropy of the laminate was observed. Additional stress relaxation tests were conducted to measure the viscoelastic response of the material.

\section{ACKNOWLEDGEMENTS}

The financial support by the Austrian Research Promotion Agency (FFG project No. 843685) is gratefully acknowledged. 


\section{REFERENCES}

[1] S. Sarva, M. Boyce. Mechanics of polycarbonate during high-rate tension. Journal of Mechanics and structures, mathematical sciences publisher 2(10):1853-1880, 2007.

[2] H. Azman, W. YeanJwu. Mechanical properties of high impact abs/pc blends - effect of blend ratio. 2005.

[3] R. Krache, I. Debbah. Some mechanical and thermal properties of pc/abs blends. Materials Sciences and Applications 2(5):404-410, 2011.

[4] R. Greco, M. Astarita, L. Dong, A.Sorrentino. Polycarbonate/abs blends: Processability, thermal properties and mechanical and impact behavior. Polymer Engineering and Science 27(9):632-639, 1987.

[5] W. Chiang, D. Hwung. Properties of polycarbonate/acrylonitrile-butadiene-styrene blends. Advances in Polymer Technology 13(4):259-274, 1994.

[6] M. Jerabek, Z. Major, R. Lang. Strain determination of polymeric materials using digital image correlation. Polymer Testing 29(3):407-416, 2010.

[7] B. Demırel, A. Yaraş, H. Elçıçek. Crystallization behavior of pet materials. BAUU Fen Bil Enst Dergisi Cilt 13(1):26-35, 2011. 